\title{
CLASSIFICAÇÃO ANATÔMICA DAS ENCEFALOCELES ANTERIORES
}

\author{
EDUARDO BARRETO*, JACKELINE BARBOSA**, CARLOS TELLES***
}

\begin{abstract}
RESUMO - Os autores apresentam uma classificação anatômica para as encefaloceles anteriores. A importância do conhecimento topográfico no diagnóstico e tratamento dessas anomalias \& realçado para que sejam prevenidas complicações durante a investigaçăo de protrusões crânio-faciais.
\end{abstract}

PALAVRAS-CHAVE: encefaloceles anteriores, classificação, conduta.

Anatomical c'assification of anterior encephaloceles.

SUMMARY - The authors present an anatomical classification of the anterior encephaloceles. The importance of a topographic knowledge of such anomalies in their diagnosis and treatment is emphasized in order to avoid complications during the investigation of a cranio-facial protrusion..

KEY WORDS: anterior encephaloceles, classification, management.

A encefalocele é uma protrusão do conteúdo do crânio além dos seus limites normais, através de uma má-formação óssea congênita associada 9 ou, mais raramente, através de forames ou fissuras normais ao crânio. A etiopatogênese desta anomalia é ainda desconhecida. $\mathbf{E}$ provável que agentes teratogênicos estejam envolvidos, agindo sobre o fechamento do tubo neural primitivo 2 Altas doses de vitamina $A^{*}$, agentes virais $1 s$, radiação 5 , salicilatos, hipertermia, hipoxia e outros agentes 12 produziram estas má-formações em experiências laboratoriais porém seus mecanismos exatos são ainda discutidos 9,10 . O conteúdo de uma encefalocele é variável, podendo apresentar desde meninges e líquido cefalorraquidiano somente, até a inclusão de tecido encefálico, partes do ventrículo 9, vasos e plexo coróide 2. Mesmo estruturas vitais da área hipotálamohipofisária podem estar comprometidas 4,15. Embora a ocorrência das encefalo celes em geral seja estimada em 1 a cada 4000 nascimentos 12 , parece provável que esta frequência seja consideravelmente maior 8,11. A localização anatômica desta anomalia conjuntamente a outros fatores - como conteúdo do saco herniário, extensão da má-formação, lesões associadas do sistema nervoso central (SNC) e/ou sistêmicas, entre outros - é determinante do tratamento e prognóstico do paciente. Por esse motivo, o conhecimento das diversas áreas anatômicas onde têm sido verificadas as encefaloceles se impōe como algo de vital importância.

Reunimos neste estudo os vários tipos descritos de encefaloceles da região anterior do crânio, propondo uma classificação, modificada de Matson ${ }^{9}$ e Sun-

* Professor Auxiliar, Setor de Neuroanatomia, Departamento de Anatomia e Disciplina de Neurocirurgia do Hospital Universitário Pedro Ernesto (HUPE) da Universidade do Bstado do Rio de Janeiro (UERJ); ** Estagiária, Setor de Neuroanatomia, Departamento de Anatomia, UERJ; ** Professor Adjunto, Chefe da Disciplina de Neurocirurgia, HUPE-UERJ. Trabalho realizado com apoio da FAPERJ (Processo E-29/170.077/90). Aceite: 01-agosto-1992.

Dr. Eduardo Barreto - Setor de Neuroanatomia, Departamento de Anatomia, UERJ - Av. Prof. Manoel de Abreu 48 - 20550-170 Rio de Janeiro RJ - Brasil. 
wanwela 13, mais abrangente e, ao mesmo tempo, mais simplificada. A nomenclatura é baseada exclusivamente na localização óssea que dá passagem ao saco herniário. Classificamos assim, em um só grupo, tanto as encefaloceles que protruem através dos ossos da face como as que atravessam a base do crânio e a calvária em suas porções anteriores. Propomos a consideração das encefaloceles anteriores como sendo aquelas que ocorrem na área situada adiante dos seguintes limites, incluindo-se a face (Fig. 1): - limite superior, margem anterior dos ossos parietais; - limite inferior, margem anterior dos ossos temporais.

\section{CLASSIFICACÃO}

1. Fonticulo anterior. Ocorre através da área de junção entre os ossos parietais e os ossos frontais 9 (Fig. 2).

2. Interfrontal. Ocorre através de um defeito nos ossos frontais, na regiăo da sutura metópica. O osso frontal que margeia os ossos nasais, inferiormente, permanece intacto, enquanto o defeito ósseo pode se fundir ao fontículo anterior, superiormente 9 (Fig. 2).

3. Temporal. A sua localização é imediatamente posterior à margem lateral da órbita, através do ptério (Fig. 3) ou fontículo ântero-lateral (área de união entre os ossos frontal, parietal e temporal, bem como asa maior do osso esfenóide). Esta encefalocele é, geralmente, sessil e tende a deformar progressivamente o olho ipsilateral e a orelha, à medida em que vai crescendo na área zigomática, em direção à face. Na radiografia, pode-se evidenciar o defeito ósseo no ptério, assim como deformidade na parede orbitária ipsilateral e na asa esfenoidal 9.

4. Transetmoidal. A encefalocele atravessa um defeito na lâmina crivosa do osso etmóide 14,17 e tende a se localizar na cavidade nasal, geralmente próxima ao septo e medial à concha média 9. E denominada por alguns autores de intranasal ou nasofaringea 9 (Fig. 4).

5. Effeno-etmoidal. Atravessa um defeito que atinge os ossos esfenóide e etmóide, seja apenas em sua área de junção 9 ou atingindo em grande extensão ambos os ossos7 (Fig. 4), tendendo a localizar-se na boca ou epifaringe 16 , sendo por isso também denominada de esfenofaríngeia 9. Geralmente, contém estruturas vitais e associa-se a uma variedade de anomalias cerebrais e a fenda palatina 7.

6. Transesfenoidal. Atravessa o osso esfenóide em qualquer de suas partes, podendo o defeito ósseo estar localizado, inclusive na sela turca (Fig. 4). Esta encefalocele está, da mesma forma que a anterior, assaciada à fenda palatina, por onde poderá alcançar a faringe 10 . E também denominada esfenofaríngea por alguns iatores 9 .

7. Esfeno-orbital. Atravessa um forame normal (fissura orbitária superior e/ou forams óptico) 9 ou um defeito entre a asa esfenoidal $\theta$ a superficie orbital do csso frontal (Fig. 2), entrando na parte posterior da órbita (encefalocele orbital posterior) e acarretando sintomas de massa retrobulbar 11,17 . O saco herniário pode, após atravessar a fissura orbital superior, passar através da fissura orbital inferior para a fossa pterigopalatina, neste caso sendo denominada esfenomaxilar $14,15,17$.

8. Encefaloceles fronto-etmoidais. Estas encefaloceles têm como característica a presenca de defeito ósseo interno que nem sempre corresponde ao defeito ósseo externo. 0 defeito interno, comum aos três subtipos, localiza-se na região anterior da base do crânio 6 , entre os ossos frontal e etmóide (Fig. 4). Em cerca de 50\% dos casos, há uma abertura única mediana, na área correspondente ao forame cego, com a crista galli localizada na borcia posterior do defeito. Aproximadamente $25 \%$ dos pacientes têm uma abertura em cada lado da linha mediana, anterior à lámina crivosa, situando-se a crista galli posteriormente à ponte óssea entre os dois defeitos. Os demais casos apresentam uma única abertura anterior à lâmina crivosa. O defeito externo difere para cada um dos três subtipos 9.

8a. Nasofrontal. A abertura óssea externa localiza-se no násio, entre o osso frontal acima, e os ossos nasal e etmóide abaixo (Figs. 2 e 3). Os ossos nasais, a cartilagem nasal e os processos frontais do osso maxilar podem manter relação normal 9, mas é possível ocorrer diastase ou cisão dos ossos nasais ou do processo frontal do osso maxilar 13. A parede medial da orbita pode estar desviada lateralmente e a ponte nasal pode estar alargada. A fossa craniana anterior pode aprofundar-se na linha média, em decorrência do deslocamento inferior dos ossos etmóides em réação ao teto da órbita, de qualquer lado9. O saco herniário é, habitualmente, único e pedunculado 9 , localizando-se na glabela ou raiz nasal 13. 

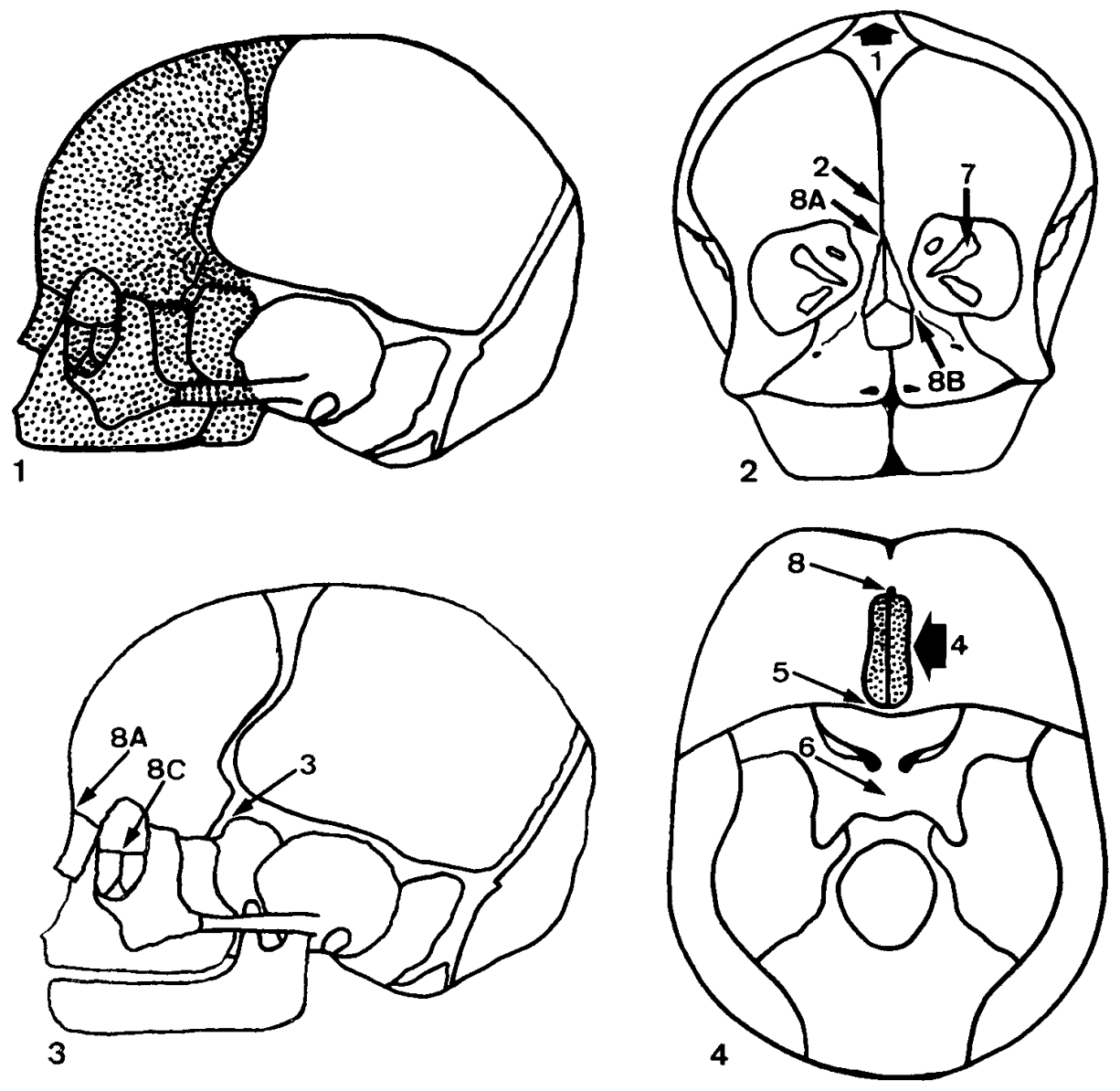

Fig. 1. Area de ocorrência das encefaloceles anteriores. Em:

Fig. 2. Fontículo anterior (1), interfrontal (2), esfeno-orbital (7), nasofrontal (8A), naso-etmoidal (8B).

Fig. 3. Temporal (3), nasofrontal (8A), naso-orbital (8C).

Fig. 4. Transetmoidal (4), esfeno-etmoidal (5), transesfenoidal (6), fronto-etmoidais (8).

8b. Naso-etmoidal. A má-formação óssea está localizada entre as porções óssea e cartilaginosa do nariz 14,17 (Fig. 2). O canal ósseo é formado pelos ossos nasais e pelo processo frontal do osso maxilar, superiormente, a cartilagem nasal e o septo nasal presos internamente ao osso etmóide, inferiormente e a parede lateral da órbita lateralmente. A parede orbitária pode ser membranosa, ao invés de óssea. O saco herniário localiza-se mais inferiormente que o saco nasofrontal e pode se estender para o canto interno de ambos os olhos, produzindo massa bilobulada. Estia forma de encefalocele é mais frequentemente séssil 9 e está geralmente associada a assimetrias da fossa anterior 13 .

8c. Naso-orbital. A abertura 6́ssea externa está localizada na porção ântero-inferior da parede medial de uma ou de ambas as órbitas, entre os ossos frontal, lacrimal e etmóide. (Fig. 3). Os ossos frontais, nasais e a cartilagem nasal têm relação normal entre si. A via de passagem para o colo do saco herniário é longa. O processo frontal do osso maxilar forma a parede anterior do canal, enquanto o osso lacrimal e a lâmina papirácea do osso etmóide formam a margem posterior do defeito. A massa exteriorizada pode ser única ou bilateral 9 e aparece preenchendo o aspecto ântero-inferior da orbita, deslocando o olho inferior e lateralmente e o saco lacrimal medialmente (encefalocele orbital anterior)13. 


\section{COMENTARIOS}

As encefaloceles nem sempre apresentam-se como má-formação isolada. Outras anomalias estão frequentemente associadas, como: fenda palatina e/ou labial 7,y, agenesia do corpo caloso ', coloboma de nervo optico ‘,y, obstrução do dicto lacrimal 16, anoftalmia 7, hipertelorismo 3,7 , nariz bifido 7,16 , hidrocefalia 9 , dextrocardia 12, agenesia renal, entre outras. Apesar de, no hemisfério ocidental, cerca de 80 a $90 \%$ das encefaloceles ocorrerem na regiăo occipital 9,10 (aqui consideradas como encefaloceles posteriores) a importância do enfoque às encefaloceles anteriores advém do fato de que estas, em suas diversas apresentações topográficas, podem passar desapercebidas no exame físico de uma criança. Nem sempre há deformações faciais que possam sugerir a presença de máformação óssea subjacente 3 .

Algumas encefaloceles têm seu saco herniário localizado inclusive nas fossas nasais ou na faringe, simulando tumores 13. Assim, são conduzidas terapeuticamente de tal forma a por em risco a vida desses pacientes $3,8,9,15$, dado que os tumores da região facial sem comunicação com o SNC têm, em sua maioria, acesso cirúrgico através das cavidades nasal ou oral 6 . Já, nas encefaloceles desta região, geraimente, o acesso intracraniano é o mais indicado 6,10,11,15. Ultimamente, a abordagem da má-formação por via transpalatal, especialmente em casos de comprometimento extenso da base do crânio, tem obtido sucesso desde que a cirurgia seja fundamentada em um diagnóstico de encefalocele e que a devida cobertura antibiótica seja instalada 7. Vários autores 3,15 destacam a importância de considerar a possivel presença de encefalocele em pacientes com diagnóstico de tumores intranasais, especialmente crianças que apresentam meningite bacteriana de repetição e rinorréia, na ausência de história traumática ou cirúrgica pregressa, ou após intervenção cirúrgica intranasal para retirada dos tumores. Love 8 relata o caso de uma paciente que morreu após uma "polipectomia" de rotina durante a qual uma encefalocele foi removida, conforme demonstraram os achados patológicos.

Cabe ressaltar que as encefalcceles, ao contrário dos pólipos e gliomas nasais, são compressíveis e pulsáteis 7, expandindo-se durante o choro 6,7 ou à compressão das veias jugulares (sinal de Furstenberg) $y$, quando localizadas na faringe 7. Além disto, os pólipos raramente ocorrem em recém-natos 4,9. Em relação à localização, os pólipos situam-se lateralmente à concha média nasal, enquanto a localização de uma encefalocele é, geralmente, medial 9 .

Quanto às encefaloceles que protruem através de defeitos na base do crânio, é possível que, à exceção do alargamento da ponte nasal, hipertelorismo e/ou maior diâmetro bitemporal, não haja outro indício externo de sua presença. $O$ diagnóstico pode ser efetuado com base em alterações radiológicas $\mathbf{9}$. Por outro lado, ao contrário do que se passa com as encefaloceles posteriores, desde que năo ocorram complicações como infecções e hidrocefalia e dependendo do grau de má-formaçōes eventualmente associadas, nos pacientes com encefaloceles anteriores pode-se esperar um desenvolvimento intelectual normal 12 .

A abordagem anatômica das encefaloceles anteriores facilita seu entendimento, bem como o diagnóstico precoce da má-formação, prevenindo-se então as possiveis complicaçóes de uma abordagem terapêtica inadequada.

\section{REFEARENCIAS}

1. Blumenfeld R, Skolnick EM. Intranasal encephaloceles. Arch Otolaryngol 1965, 82:525-531.

2. Ceccarelli G, Frugoni P, Briani S. Trattado italiano di patologia chirurgica, Vol III. Padova: Piccin, 1964, p 23-26.

3. Choudhury AR, Taylor JC. Primary intranasal encephalocele: report of four cases. $J$ Neurosurg 1982, $57: 552-555$.

4. Davis CH Jr, Alexander E Jr. Congenital nasofrontal encephalomeningoceles and teratomias: review of seven cases. $J$ Neurosurg 1959, $15: 365-377$.

5. Elwood JM. Comment on «Anencephalus, drinking water, geomagnetism and cosmic radiation». Am J Epidemiol 1979, 109:98-99.

6. Karma P, Raesaenen O, Kaerjae J. Nasal gliomas: a review and report of two cases. Laryngoscope 1977, 87:1169-1177. 
7. Lewin ML. Sphenoethmoidal cephalocele with cleft palate: transpalatal versus transcranijal repaìr. J Neurosurg 1983, 58:924-931.

8. Love GL. Intranasal encephalocele masking as a nasal polyp in an adult patient. Arch Otolaryngol 1983, 109:420-421.

9. Matson DD. Neurosurgery of infancy and childhood, Ed. 2. Springfield: Charles C Thomas, 1969, p 61-75.

10. Noramn MG, Ludwin SK. Congenital malformations of the nervous system. In Davis RL, Robertson DM (eds): T'extbook of Neuropathology Ed 2. Baltimore: Williams \& Wilkins 1991, p 207-281.

11. Rai.man NU. Nasal encephaioceles: treatment by transcranial operation. J Neurol Sci $1979,42: 73-85$.

12. Reigel DH. Encephalocele. In Section of Pediatric Neurosurgery, American Association of Neurological Surgeons: Surgery of the developing nervous system. New York: Grune \& Straton, 1982, p 49-60.

13. Sunwanwela C, Sunwanwela N. A morphological classification of sincipital encephalomeningocele. J Neurosurg 1972, 36:201-211.

14. Tessier P. Anatomical ciassification of facial, cranio-facial and latero-facial clefts. J Max Fac Surg 1976, 4:69-92.

15. Walker E, William WM, Simpson JR. Intranasal encephaloceles: survey of problem with recomendations for reducing mortality. Arch Otolaryngol 1952, 55:182-187.

16. Willianson AP, Blattner RJ, Robertson GG. The relationship of viral antigen to virus induced defects in chick embryo: Newcastle disease virus. Dev Biol 1985, 12:498-519.

17. Willianson WP, Barelli PA. Intranasal encephalocele. J Neurosurg 1951, 8:231-235. 